\title{
An integrated study on the coseismic and post-seismic deformation of the 2010 Yushu earthquake based on InSAR analysis
}

\author{
Qu Chunyan*, Shan Xinjian, Zuo Ronghu, Zhang Guohong and Liu Yunhua \\ State Key Laboratory of Earthquake Dynamics, Institute of Geology, China Earthquake Administration, \\ Beijing 100029, People's Republic of China. \\ *Corresponding author.e-mail: dqyquchy@163.com
}

MS received 17 February 2016; revised 30 May 2018; accepted 7 June 2018; published online 23 February 2019

We carry out an integrated study on coseismic and post-seismic deformation caused by 2010 Yushu earthquake sequence, including both mainshock and aftershocks, by using multi-scene ENVISAT/ASAR data on two adjacent tracks. We map the extended deformation region to the west of mainshock and show the westward extension of seismogenic fault of mainshock. Based on our whole deformation field derived from mosaic interferograms, the total length of seismogenic fault reaches $\sim 103 \mathrm{~km}$ longer than $\sim 71 \mathrm{~km}$ suggested by the previous report. Several coseismic interferograms with different time baselines have similar deformation patterns, which indicate that the influence of aftershocks and post-seismic slip on coseismic deformation field is limited. Also, we observe a clear and separate deformation area, $\sim 38 \mathrm{~km}$ to the west of the mainshock epicentre, with maximum displacement of $\sim 9 \mathrm{~cm}$. The localised deformation is composed of two patches with opposite motion directions, where an aftershock cluster with at least 47 events (>Ms 3.0) occurred. We infer that this localised deformation is caused by aftershocks ruptured on a blind active fault. While a weak post-seismic deformation band along main rupture zone near mainshock epicentre is likely attributable to short-term afterslip.

Keywords. InSAR; Yushu earthquake; coseismic; aftershock; post-seismic.

\section{Introduction}

The 14 April 2010 Yushu Ms 7.1 (Mw 6.9) was a left-slip event on the 500-km long, NW-trending Ganzi-Yushu fault (Li et al. 1995; Wen et al. 2003; Zhang et al. 2003; Peng et al. 2006; Gan et al. 2007 ) in the interior of Tibetan Plateau (figure 1) with an epicentre at $33.2^{\circ} \mathrm{N}$ and $96.6^{\circ} \mathrm{E}$ (Jiegu town of Yushu county) and a focal depth of $14 \mathrm{~km}$ (Zhang et al. 2010). As of 23 June 2010, 82 aftershocks $(\mathrm{Ms} \geq 3.0)$ were recorded, of which the largest one, Ms 6.4 (Mw 6.1), happened only 96 min after the mainshock at the same location. Field investigations found surface ruptures along the causative fault, striking at $300^{\circ}$, with a total length of $65 \mathrm{~km}$ and maximum left-slip of $2.4 \mathrm{~m}$ (Chen et al. 2010; Sun et al. 2012).

There have been many InSAR (Interferometric Synthetic Aperture Radar) studies made on this earthquake using ALOS/PALSAR or ENVISAT/ ASAR data, which focus on coseismic deformation, and inversion for fault geometry and slip distribution (Guo et al. 2010; Liu et al. 2010a, b; Shen et al. 2010; Li et al. 2011; Tobita et al. 2011; Zha et al. 2011), yielding largely similar results. The data coverage of these studies is relatively 

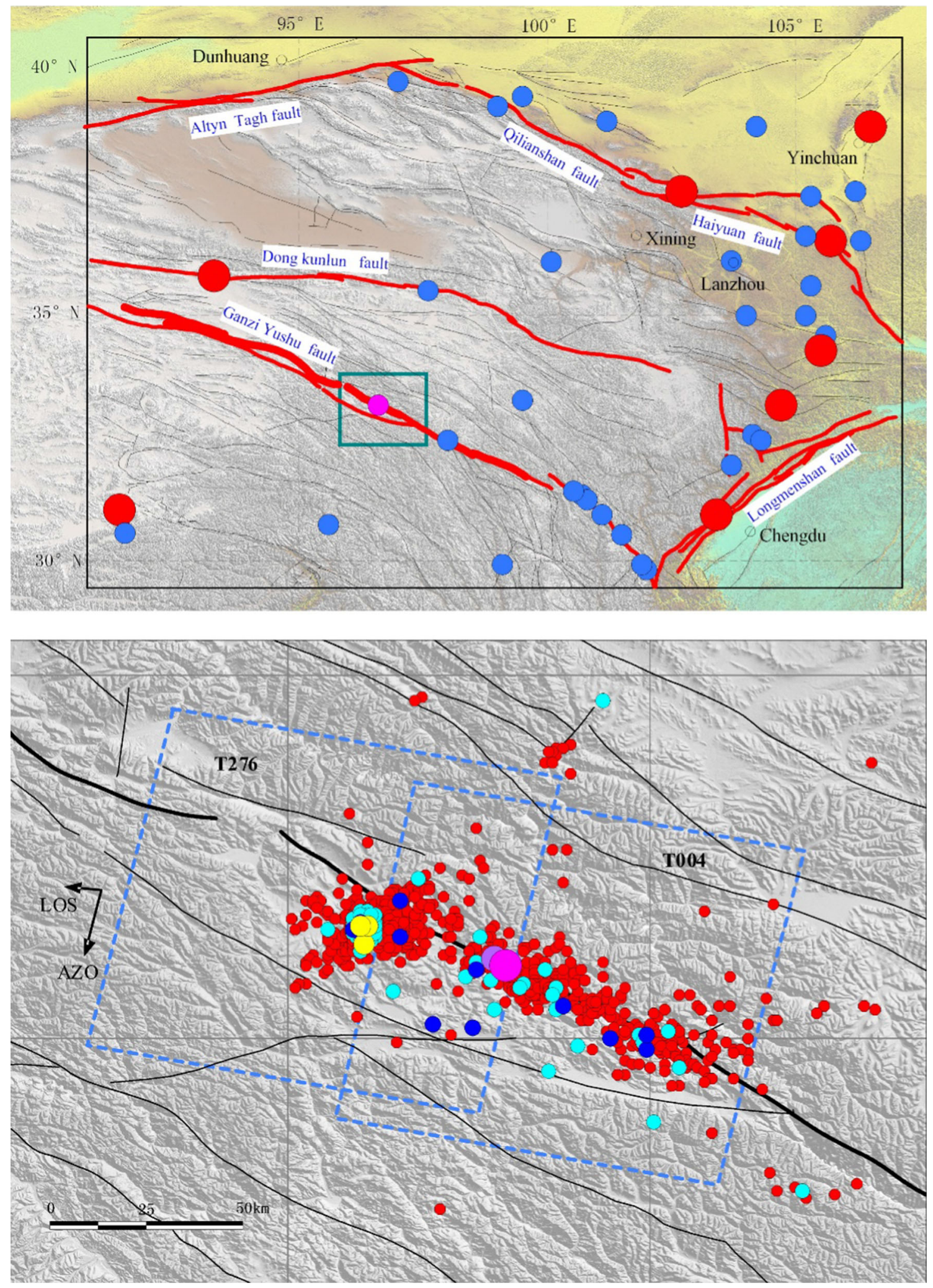

Figure 1. Upper: Tectonic setting map showing main faults, the epicentre of 2010 Yushu Ms 7.1 (pink) and historical events (red: $M \geq 8.0$, blue: $\mathrm{M}=7.0-7.9$ ). The box shows the study area. Lower: Enlarged study area. Black lines are faults, the thick black line is the Ganzi-Yushu fault and the coloured dots are aftershocks (red: $M<3.0$, light blue: $M=3.0-3.9$, blue: $M=4.0-4.9$, yellow: $M=5.0-5.9$, purple: $M=6.0-6.9$, pink: main shock as of 23 June 2010). Dashed rectangles denote coverage of satellite radar data of the two tracks. 
Table 1. ENVISAT/ASAR data used in this study.

\begin{tabular}{|c|c|c|c|c|c|c|c|}
\hline No. & Track & $\begin{array}{c}\text { Master scene } \\
\text { acquisition date } \\
\text { (Y-M-D) }\end{array}$ & $\begin{array}{c}\text { Slave scene } \\
\text { acquisition date } \\
(\mathrm{Y}-\mathrm{M}-\mathrm{D})\end{array}$ & $\begin{array}{l}\text { Perpendicular } \\
\text { baseline } \\
(\mathrm{m})\end{array}$ & $\begin{array}{c}\text { Time interval } \\
\text { (days) }\end{array}$ & $\begin{array}{l}\text { Time after } \\
\text { main shock } \\
\text { (days) }\end{array}$ & $\begin{array}{l}\text { Ambiguity } \\
\text { height }(\mathrm{m})\end{array}$ \\
\hline 1 & 004 & 20091103 & 20100601 & 87 & 210 & 47 & 108.1 \\
\hline 2 & 004 & 20091103 & 20100810 & -168 & 280 & 116 & 56.0 \\
\hline 3 & 004 & 20091103 & 20100914 & 219 & 315 & 150 & 42.9 \\
\hline 4 & 004 & 20100601 & 20100810 & -256 & 70 & $47-150$ & -36.7 \\
\hline 5 & 004 & 20100601 & 20100914 & 132 & 105 & $47-116$ & 71.3 \\
\hline 6 & 004 & 20100810 & 20100914 & 388 & 35 & $116-150$ & 24.2 \\
\hline 7 & 276 & 20100307 & 20100516 & 300 & 70 & 33 & 31.4 \\
\hline 8 & 276 & 20100307 & 20100620 & 190 & 105 & 67 & 49.5 \\
\hline 9 & 276 & 20100307 & 20100829 & 45 & 175 & 137 & 209.1 \\
\hline 10 & 276 & 20100516 & 20100620 & 120 & 35 & $33-67$ & 78.4 \\
\hline 11 & 276 & 20100516 & 20100829 & 265 & 105 & $33-137$ & 35.5 \\
\hline 12 & 276 & 20100620 & 20100829 & 145 & 70 & $67-137$ & 64.8 \\
\hline
\end{tabular}

small, the time intervals of raw images used for generating interferograms are generally short, and the number of repeat observation SAR images is small. In our previous work, we used only four scenes of T004 ENVISAT/ASAR data (Qu et al. 2013). As a further effort, this study employs eight scenes of adjacent descending tracks (T004, T276) of ENVISAT/ASAR data to remap the ground deformation of this event. In combination, this data forms 12 image pairs with various acquisition times, of which six pairs span pre- and post-seismic times, and the other six are purely post-seismic. Through the application of D-InSAR processing, six coseismic and six post-seismic interferograms are obtained to facilitate identification of the deformation of coseismic (mainshock), aftershock and post-seismic fault slip.

\section{SAR data and processing}

We use eight acquisitions of ENVISAT/ASAR data from two adjacent tracks to study the coseismic and short term post-seismic deformation associated with 2010 Yushu earthquake (table 1 and figure 2). The $12 \mathrm{SAR}$ image pairs are processed with the software GAMMA (Werner et al. 2000), from Switzerland, to generate 12 interferograms. Before doing this, the ASAR data was corrected by the DORIS precise orbit parameters to eliminate residual orbit errors. An algorithm considering topographic relief is employed for the co-registration of the image pairs. The topographic phases are removed by the 3-arcsec STRM (Shuttle Radar Topography Mission) DEM data after gap filling. Settings of 2-look and 10-look in the range and azimuth directions are selected and applied to the interferograms to reduce their noise. Then, many cycles of adaptive filtering, based on interferometric fringes and decreasing windows, are performed in order to enhance the signal-to-noise ratios of the interferograms and to highlight deformation fringes. The minimum cost flow algorithm, which is based on the Delaunay triangle network and suitable for low-coherence areas, is applied to unwrap the phases of the interferograms. The unwrapping is performed first on the areas of high coherence, yielding reliable phase values, before these values are subsequently used to construct the phase model for the unwrapping of the areas of low coherence. The final step is to remove the atmospheric delay phase and residual tendency phase by application of fitting methods from the interferograms. Finally, coseismic and post-seismic interferograms are derived for further analysis of the surface deformation caused by the 2010 Yushu earthquake.

\section{Co- and post-seismic deformation within the mainshock area}

\subsection{Coseismic deformation within the mainshock area (T004)}

As shown in figure $3(\mathrm{a}-\mathrm{c})$, three coseismic interferograms covering the mainshock area (T004) with different time spans after the Yushu earthquake are almost identical. All of them are characterised by fringes arranged along the NW-trending fault in an 


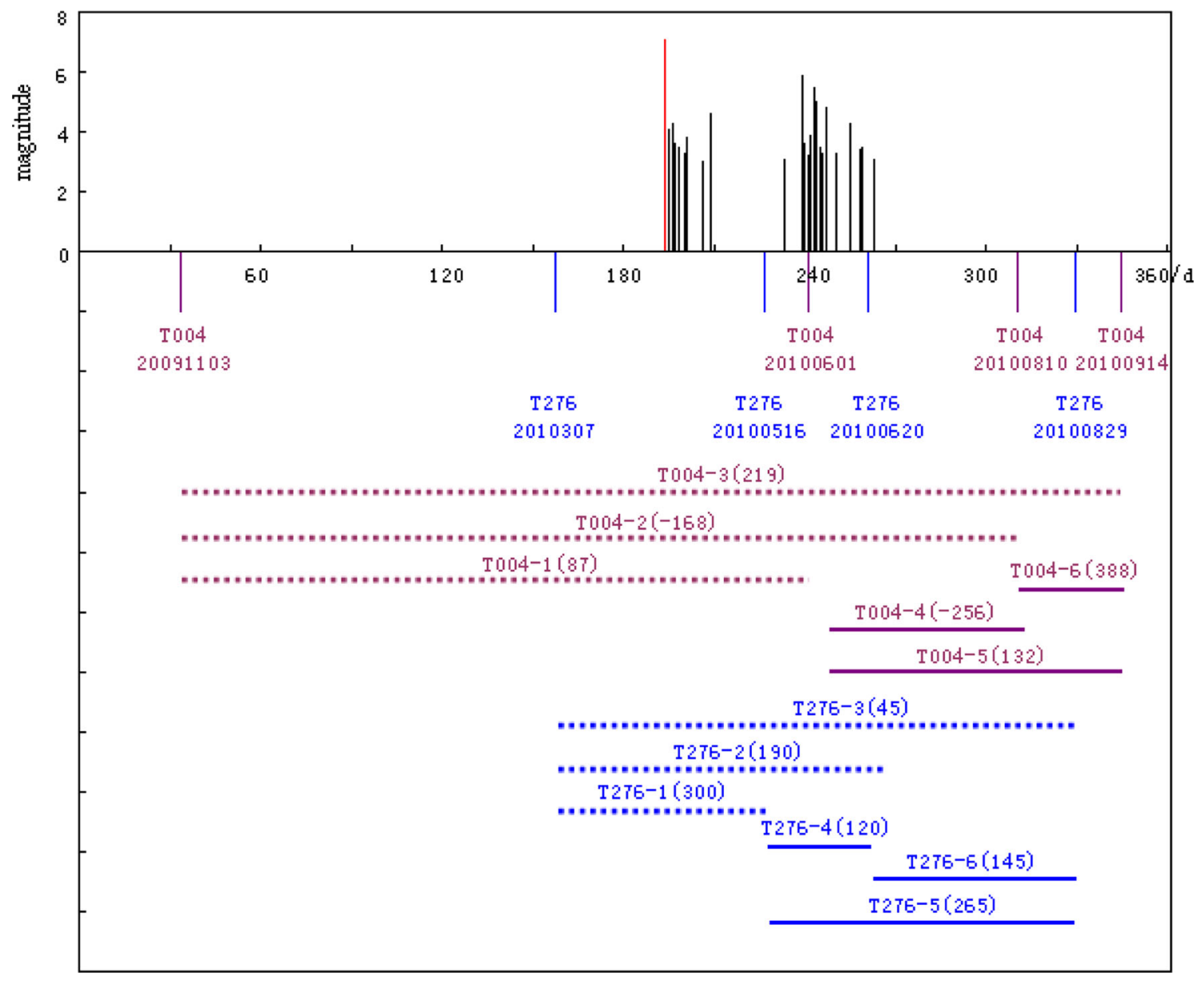

Figure 2. Upper: Mainshock (red vertical line) and aftershocks ( $M \geq 3.0$ ) as of 23 June 2010 of the 2010 Yushu event. Lower: SAR scene acquisition dates of tracks T004 and T276 (coloured vertical bars) and time intervals between two acquisitions (coloured dashed horizontal lines). Characters outside of brackets indicate the number of interferograms; the number in brackets is the perpendicular baseline of the pair.

area of about $89 \mathrm{~km} \times 57 \mathrm{~km}$. The cross fault relative deformation in LOS direction reaches about $45 \mathrm{~cm}$ (figure 4). One obvious difference among these three interferograms is that the broken stripes are observed at about $3 \mathrm{~km}$ southwest of the macro epicentre (Jiegu town) on T004-1 with the shortest time interval (figure 3a), where the interruption of fringes indicates a local deformation on the south wall of the fault. The corresponding enlarged map (figure 5a) shows a circular deformation patch with a diameter of about $12-13 \mathrm{~km}$, implying an $8.4 \mathrm{~cm}$ LOS subsidence displacement, opposite to the direction of coseismic deformation. However, this local phenomenon does not appear on the other two interferograms with later acquisition dates after the event (figure $5 \mathrm{~b}$ and c). Considering that this pattern of stripe change is inconsistent on the three interferograms, we infer that it could be due to atmospheric artifacts.

\subsection{Post-seismic deformation within the mainshock area (T004)}

From post-seismic interferograms T004-4 and T004-5 (figure 6a and b), we can identify weak post-seismic deformation which distributes in the NW direction along the main rupture zone near the epicentre. According to the visible colour difference of the interferograms (black dashed ellipses in figure $6 \mathrm{a}$ and $\mathrm{b}$ ), it is more obvious on the interferogram T004-5 which contains longer time after the mainshock. But this weak deformed strip is absent from the interferogram T004-6 (figure 6c). We think this phenomenon reflects the attenuation of afterslip in short term after Yushu mainshock. For T004-6, the first acquisition date was on 10 August 2010, nearly 4 months after the Yushu event, while the time span to its second acquisition date is only 35 days. During such a short time, no apparent post-seismic deformation is acceptable. 

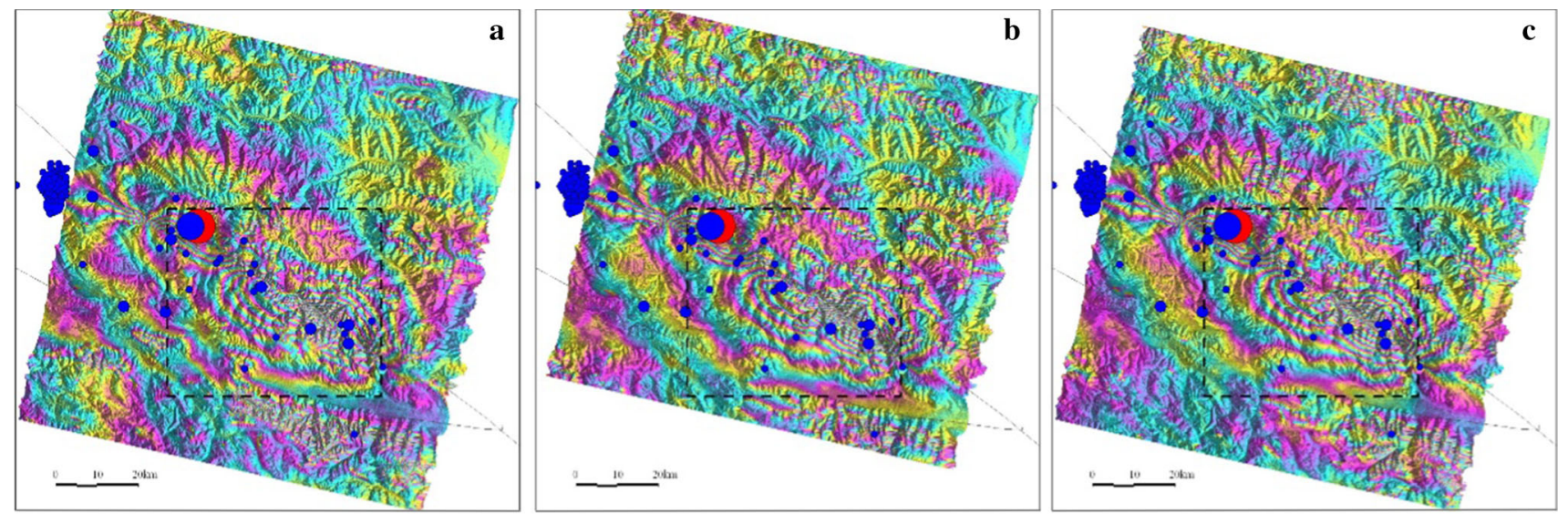

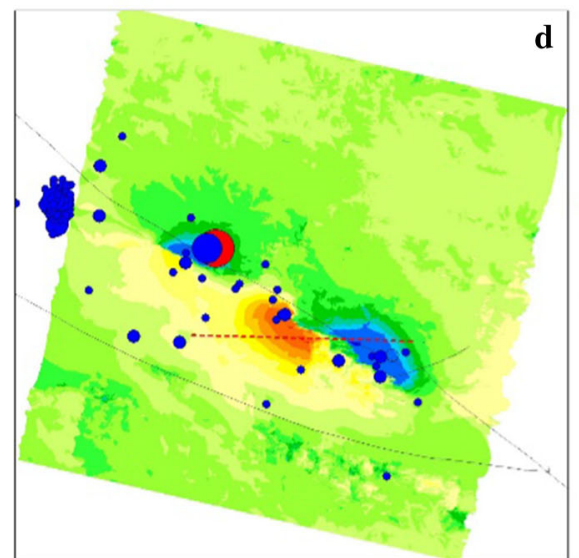

T004-1(20091103_20100601)

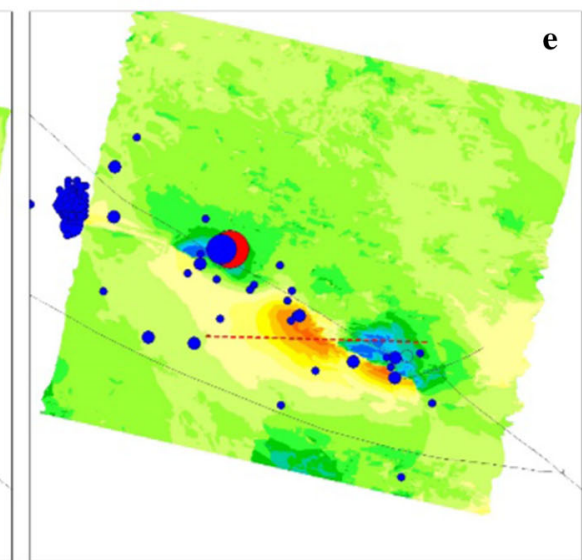

T004-2（20091103_20100810）

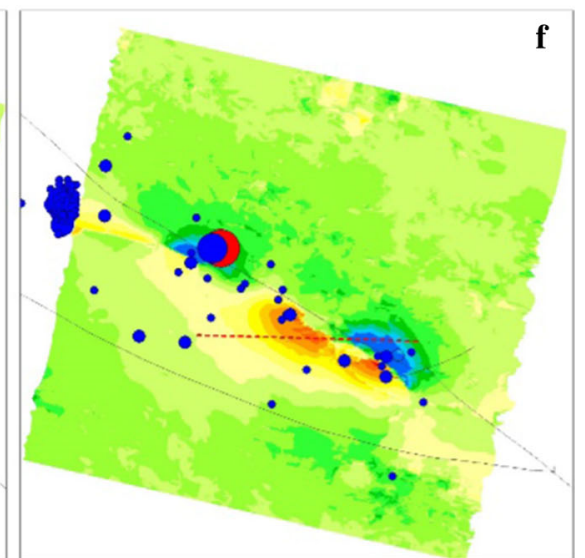

T004-3（20091103_20100914）

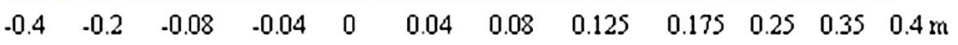

Figure 3. (a-c) Coseismic interferograms of T004 with different time intervals between image acquisitions. Red circles denote the mainshock and the blue dots of varying sizes are aftershocks $(M \geq 3.0)$. (d-f) Coseismic displacement after unwrapping corresponding to $\mathrm{a}, \mathrm{b}$, and c. The black lines are fault traces, red dotted lines denote profile location.

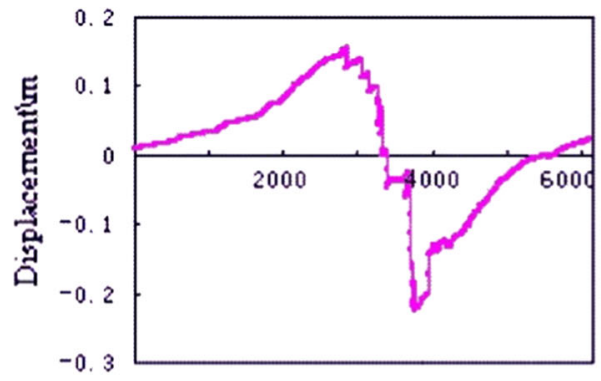

T004-1 (20091103 20100601)

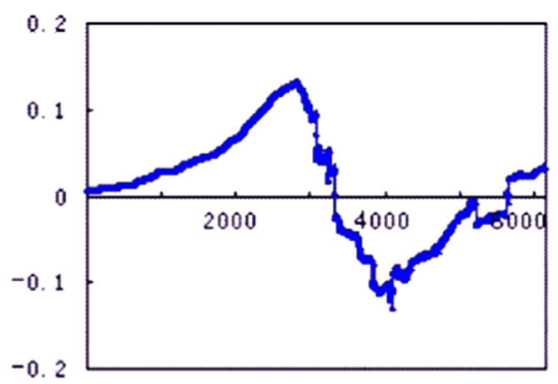

T004-2 (20091 10320100810$)$

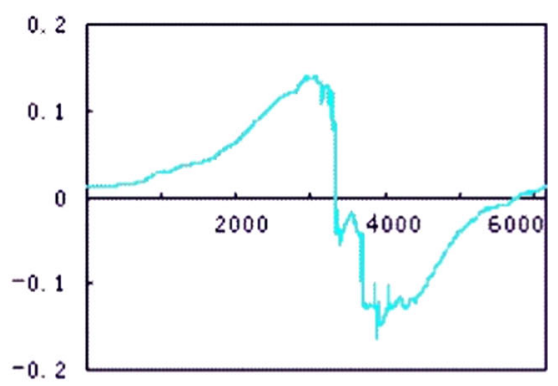

T0043 (2009110320100914)

Figure 4. Displacement profiles of three coseismic interferograms of T004 with different time intervals. The vertical axis is displacement, with unit metre, and the horizontal axis is profile length, with unit pixels. Profile locations are the red dotted lines in figure $3(\mathrm{~d}-\mathrm{f})$.

The cross fault profiles at the west of epicentre show post-seismic displacement amplitude and their variation of T004, T005 and T006 (figure 7). The values are less than $\pm 1.0 \mathrm{~cm}$ in magnitude.
Although small, they reflect the deformation trend of the two walls of the fault, e.g., negative values are present on the north wall of the fault, while positive ones appear on the south wall (figure 7 ). 


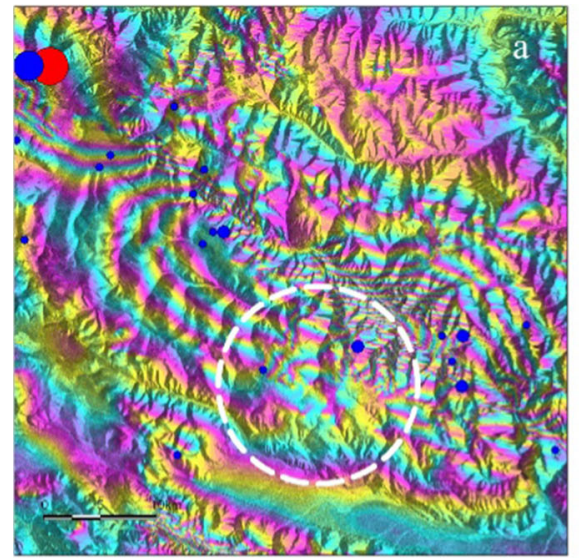

T004-1（20091103_20100601)

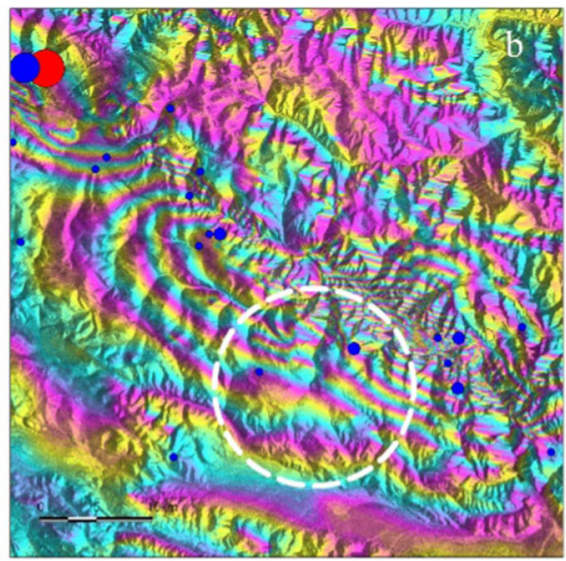

T004-2(20091103_20100810)

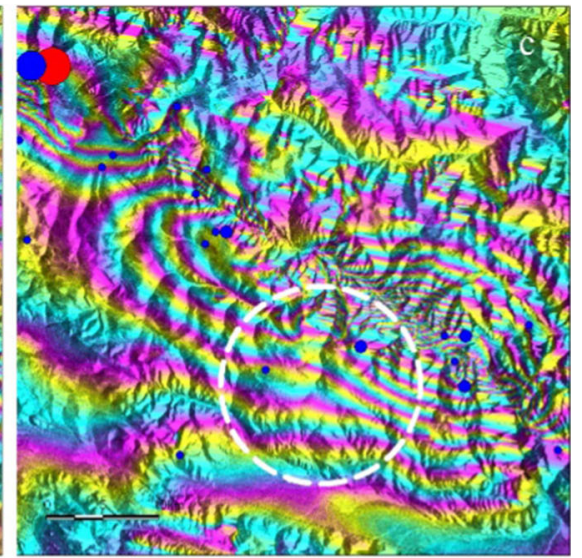

T0043（20091103_20100914)

Figure 5. Enlarged interferograms of the dashed black boxes in figure 3(a-c). White dashed circles show local deformation patches of diameters $12-13 \mathrm{~km}$ with no more than three fringes, which exhibit subsidence in the LOS direction, opposite to the coseismic deformation.
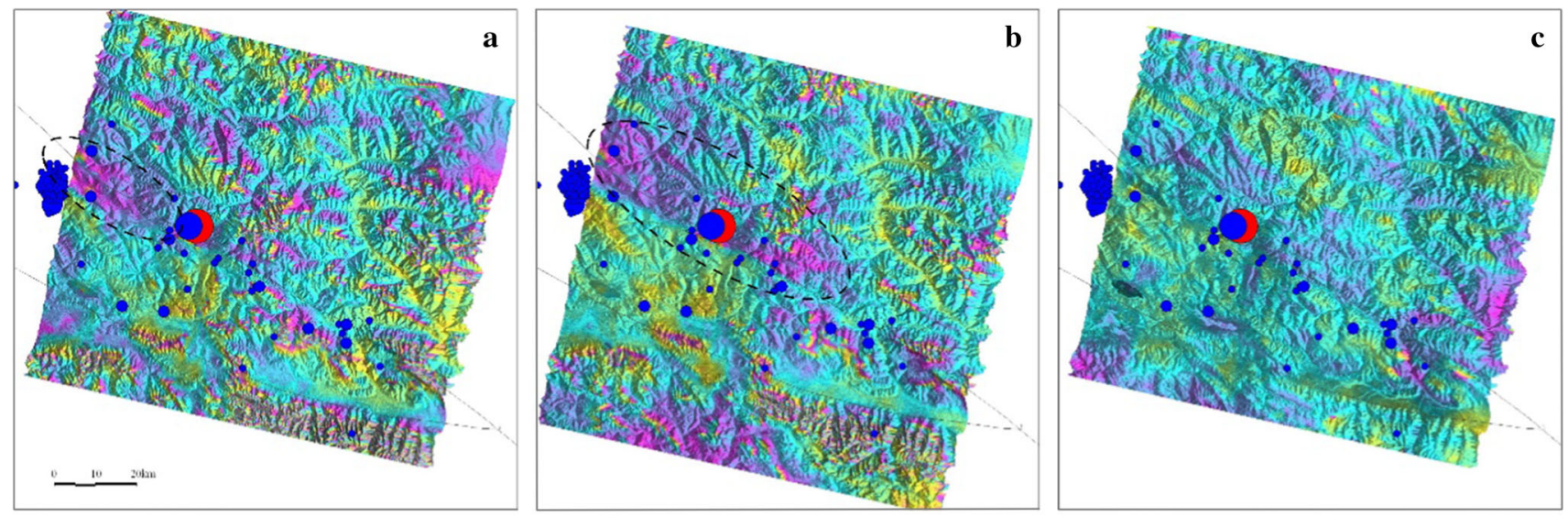

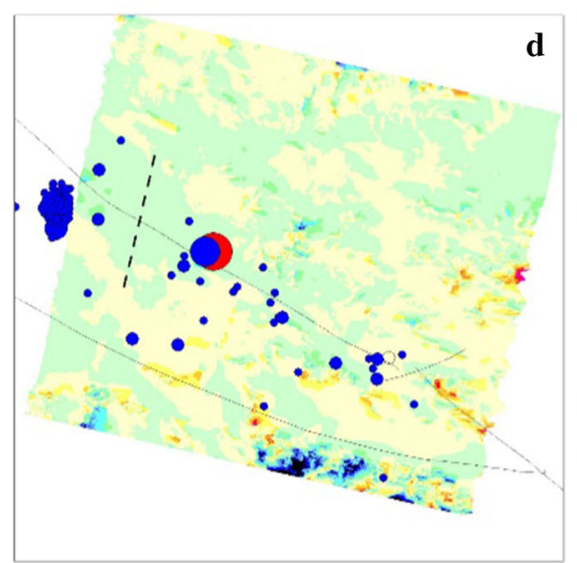

T004-4 (2010060120100810)

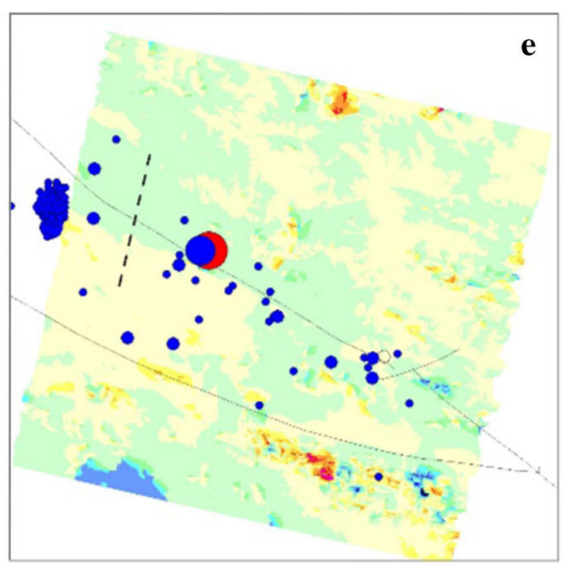

T004-5 (20100601 20100914)

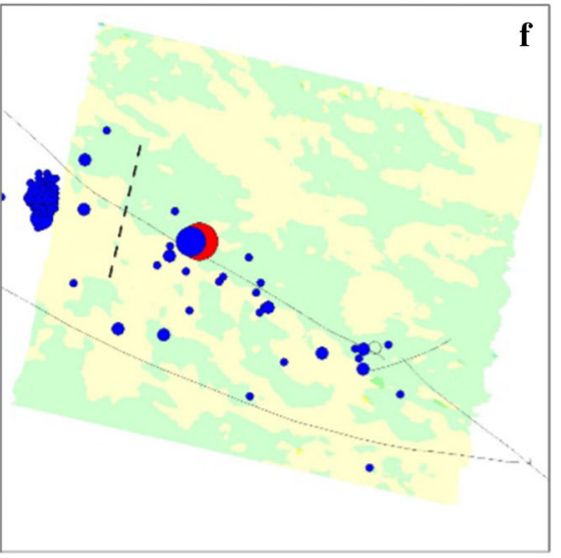

T0046 (20100810 20100914)

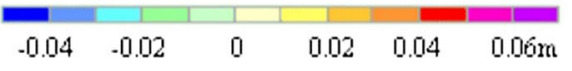

Figure 6. (a-c) Post-seismic interferograms with different time intervals of T004. $(\mathbf{d}-\mathbf{f})$ Unwrapped post-seismic deformation corresponding to $(\mathrm{a}-\mathrm{c})$, maximum displacements in LOS are approximately $\pm 1 \mathrm{~cm}$. Scattered large-value patches in distant locations are noise. The black dashed lines denote the locations of profiles across the fault. 


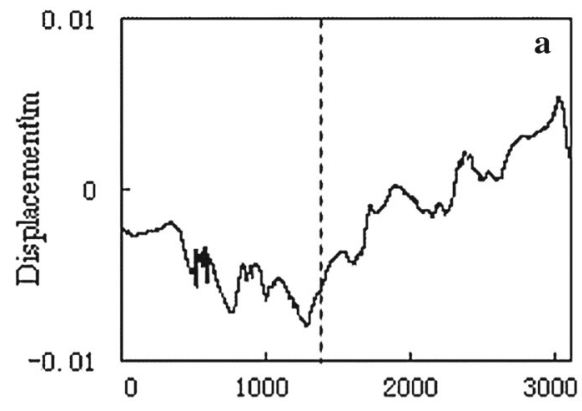

T004-4(20100601 20100810)
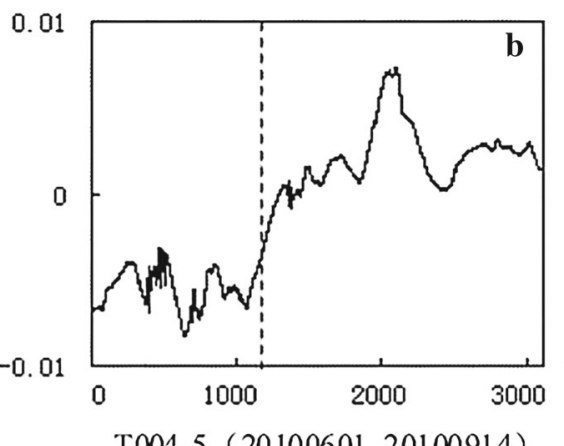

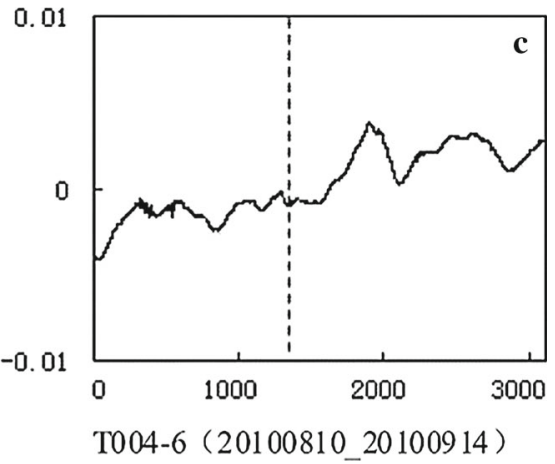

Figure 7. Displacement profiles across the fault from the T004 post-seismic interferograms. Profile locations are as shown in figure $6(\mathrm{~d}-\mathrm{f})$, with direction north to south. Grey vertical dashed lines indicate the fault location.

We can speculate that the near-field post-seismic deformation of the Mw 6.9 Yushu earthquake may last for a short time.

\section{The westward deformation area and extended fault}

\subsection{The westward extending coseismic deformation (T276)}

Three coseismic interferograms from T276 covering the western end of the mainshock area (figures 8 and 9) show consistent deformation fields with similar fringe pattern and deformation magnitude. It suggested that the coseismic deformation to the west is also significant, and its area is larger than that revealed by T004 caused by the mainshock. Note that on the two interferograms with longer post-seismic time span (T276-2, T276-3), there are two nearly parallel NWW-trending fringe belts along the aftershocks to the west of the mainshock epicentre (figure $8 \mathrm{~b}$ and $\mathrm{c}$ ). The motion of the north and south fault is opposite and the deformation gradient is abrupt with maximum relative displacement of nearly $28 \mathrm{~cm}$ in LOS (figures $8 \mathrm{~d}-\mathrm{f}$ and 9 ). We infer that the surface rupture possibly extends westward along this gradient line up to the aftershocks farther west. Actually, field investigations conducted immediately after mainshock did not reach this location. In addition, the existing active fault map of China does not suggest any known faults at this location that can be responsible for the deformation (Deng 2007). Based on the above analysis, it is possible that a blind fault ruptured subsequently or a newly triggered fault has been produced by the Yushu event at that location. This newly discovered fault, may be the conjecture of the Yushu fault, and will be investigated by future field work.

\subsection{Delayed deformation of the west end due to aftershocks (T276)}

In the west of the mainshock (T276), we produce three post-seismic interferograms (figure 10), showing clearly localised post-seismic deformation area. From the enlarged ones T276-4 and T276-5 (figure 11a, b, d and e), we can clearly identify two small ring-shaped deformation patches at the west of the mainshock epicentre; they are distributed symmetrically to the north and south, with slight differences in size and amplitude. The southern LOS subsidence and the northern LOS uplift results in the relative displacement up to $\sim 8 \mathrm{~cm}$ (figure 12 ), implying a left-slip movement consistent with the mainshock. This phenomenon is similar to that reported by Tobita et al. (2011) who detected a significant post-seismic displacement northwest of the source region and suggested that coseismic slip and post-seismic slip are spatially isolated. But this deformation pattern was not observed in interferogram T276-6 (figure 11c and f) which reflect the deformation after 2 months away from mainshock. So we infer that it may be caused by aftershocks.

After the Yushu mainshock, 82 aftershocks $(M \geq 3)$ had occurred as of 23 June 2010 (figure 10). However, most of these aftershocks are concentrated to the west of the mainshock. Furthermore, the dense aftershock swarm is just located in the reverse annular local deformation patches of interferograms T276-4 and T2765 observed by our result. Among them, there are three larger aftershocks with the magnitude of above $\mathrm{Mw} 5.0$ (Mw 5.8 in 29 May 2010, $\mathrm{Mw} 5.5$ in 3 June 2010 and $\mathrm{Mw} 5.1$ in 4 June 2010) (figure 11), which implies a possible relationship between the aftershocks and this post-seismic 

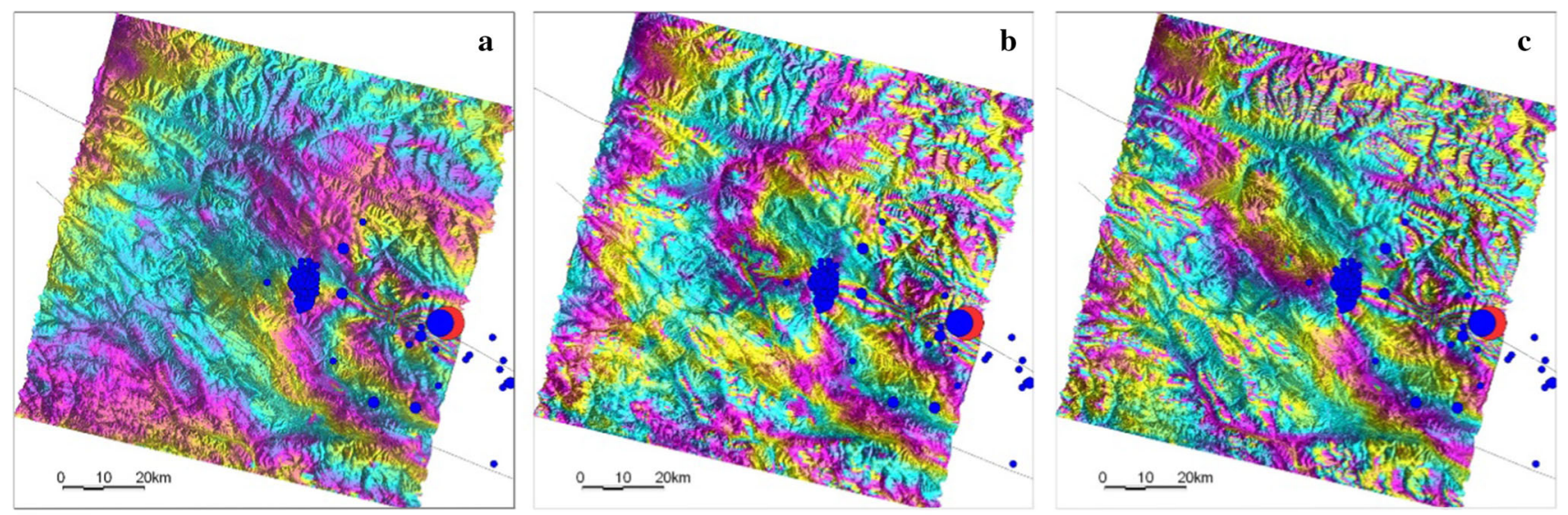

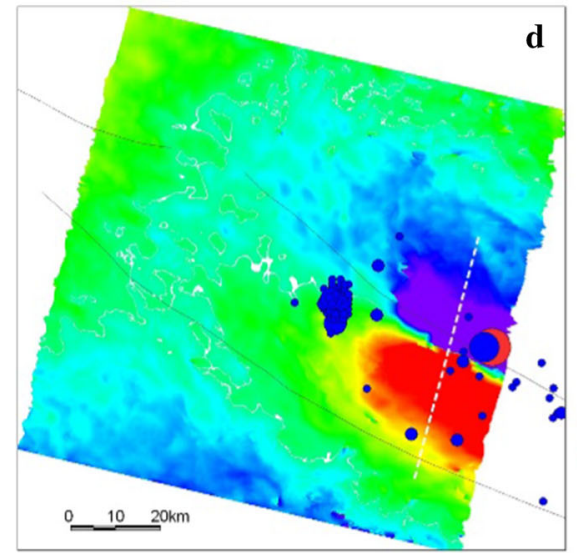

$-0.19$

T276-1(20100307 20100516)

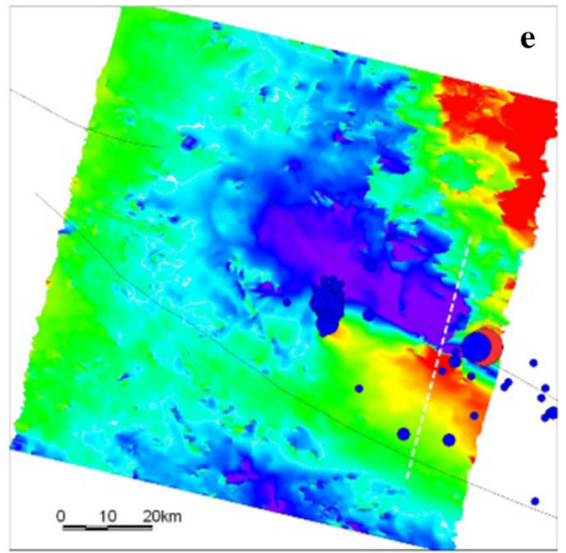

$-0.11=0.075 \mathrm{~m}$

T276-2（20100307_20100620）

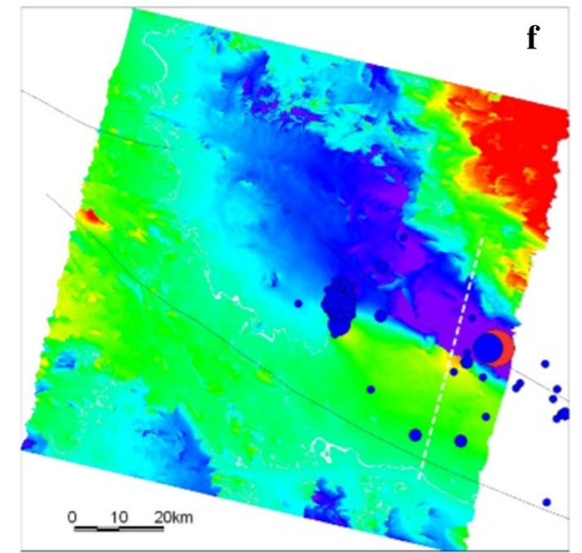

$-0.19 \square 0.08 \mathrm{~m}$

T276-3（20100307_2010829）

Figure 8. (a-c) Coseismic interferograms of T276 with different time span. Red circles denote the mainshock and the blue dots of varying sizes are aftershocks $(M \geq 3.0)$. (d-f) Unwrapped LOS displacements corresponding to (a-c), respectively. White dotted lines denote profile location, and the black lines are fault traces.
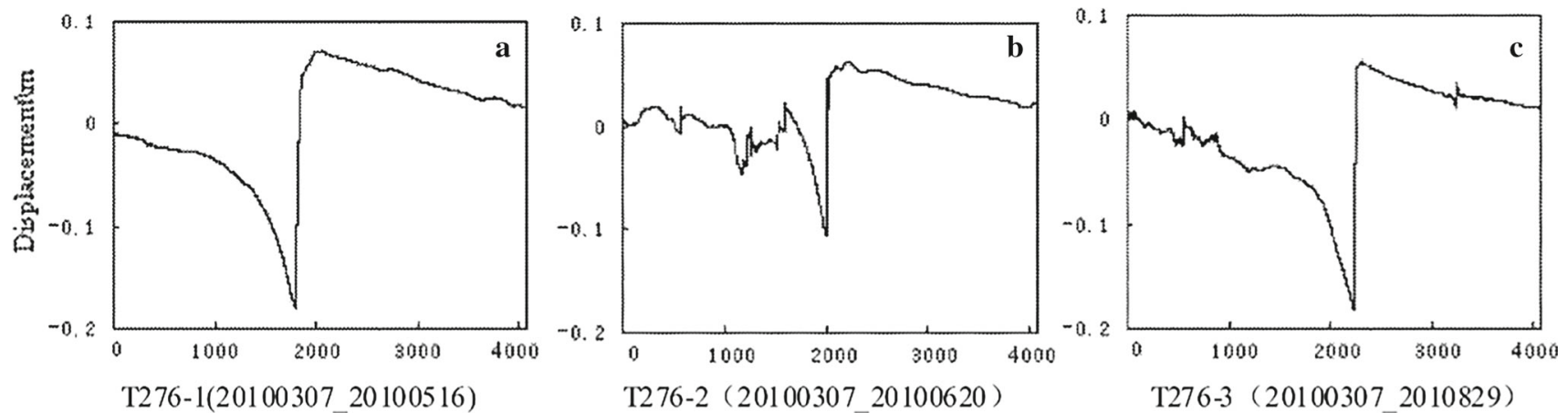

Figure 9. Displacement profiles across the fault from the T276 coseismic interferograms. The profile locations denoted by the white dashed lines in figure $8(\mathrm{~d}-\mathrm{f})$.

deformation. We speculate that there is a hidden fault between the two localised uplift and subsidence patches and it ruptures during strong aftershocks. No obvious deformation is observed in other places where the aftershocks are distributed sparsely.
4.3 The whole coseismic deformation field and westward extended fault

We choose two interferograms of T004-1 (2009110320100601) and T276-1 (20100307-20100516) with the least time span to form the whole deformation 


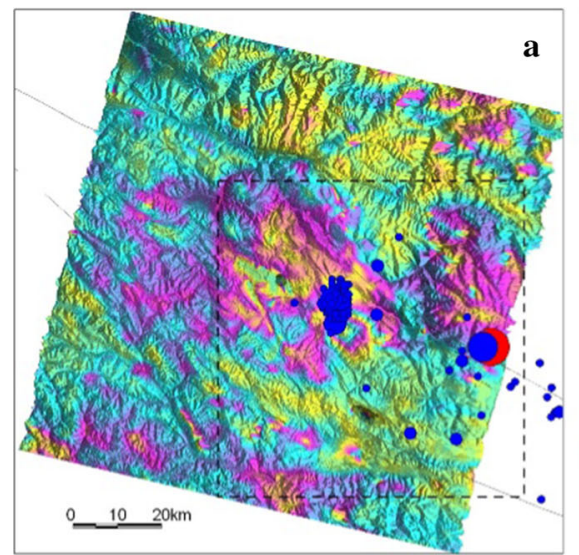

T276-4(20100516 20100620)

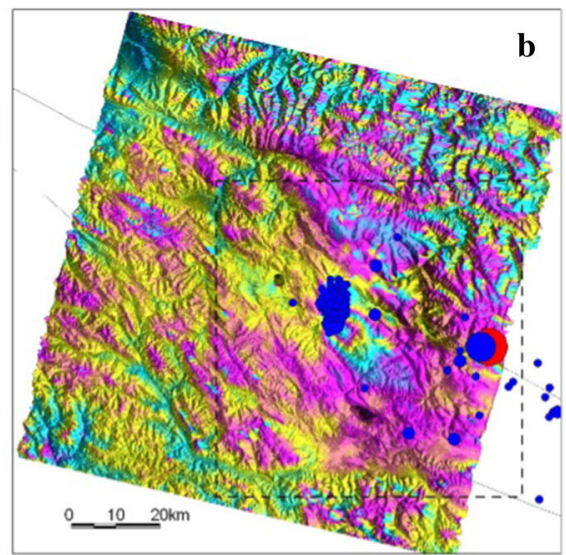

T276-5 (20100516_2010829)

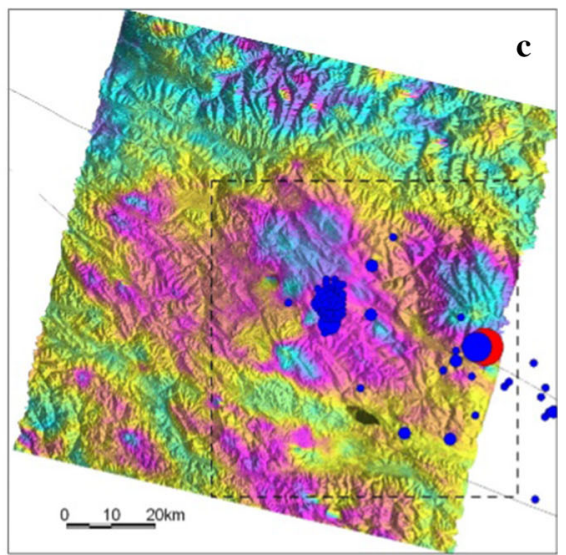

T276-6 (20100620_2010829)

Figure 10. ( $\mathbf{a}-\mathbf{c})$ Post-seismic interferograms with different time intervals of T276. The red dot is the mainshock of Yushu event and the blue dots of varying size denote the aftershocks.
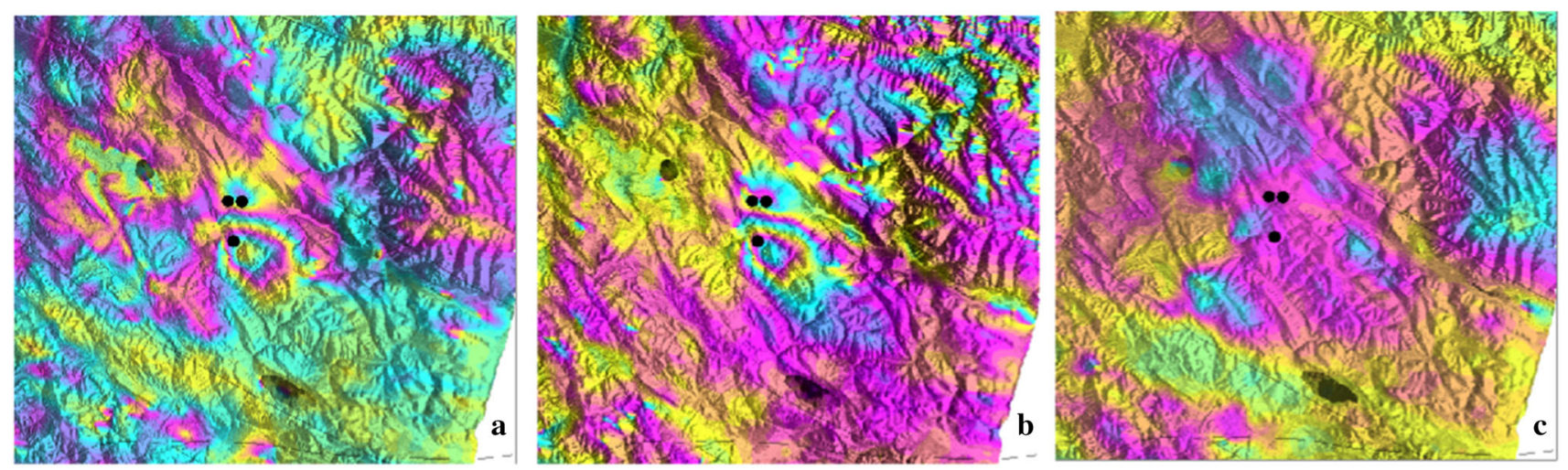

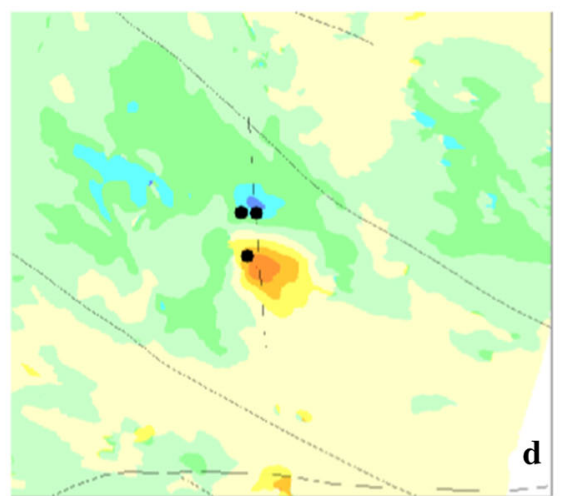

T276-4（20100516_20100620）

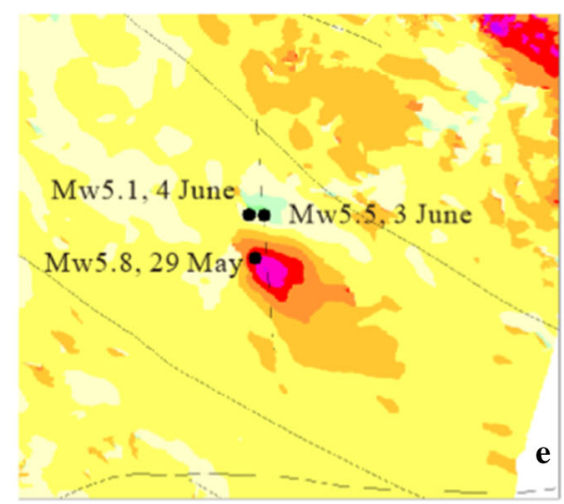

T276-5 (20100516 20100829)

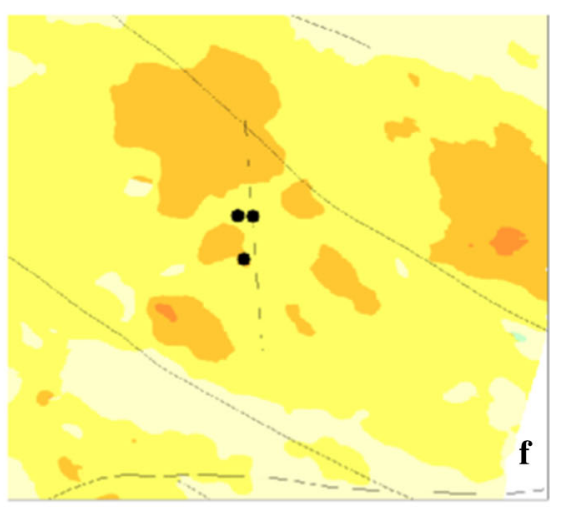

T276-4 (20100620_20100620)

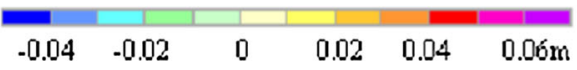

Figure 11. (a-c) Enlarged maps of the black dashed boxes in figure $10(\mathrm{a}-\mathrm{c}),(\mathbf{d}-\mathbf{f})$ unwrapped post-seismic deformation corresponding to $(\mathrm{a}-\mathrm{c})$. The black dashed lines show the profile location.

map caused by the Yushu earthquake (figure 13). The mosaic interferogram covers an area of about $110 \mathrm{~km} \times 74 \mathrm{~km}$ (black dashed box in figure 13), larger than that obtained from T004 alone, which is $89 \mathrm{~km} \times 57 \mathrm{~km}$ (white dashed box in figure 13). The total interpreted fault trace is $\sim 103 \mathrm{~km}$, with $\sim 32 \mathrm{~km}$ westward extended fault, longer than the previously estimated rupture zone form T004 alone (figure 14). This demonstrates that the mosaic interferogram from two adjacent tracks (T004 and T276) can reveal the scope of the deformation and the length of the 


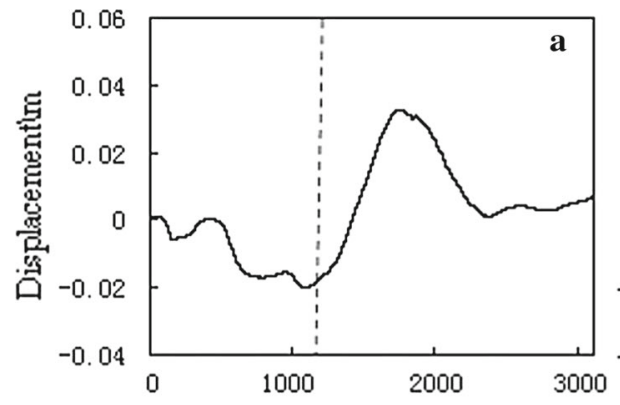

T276-4 (20100516_20100620)

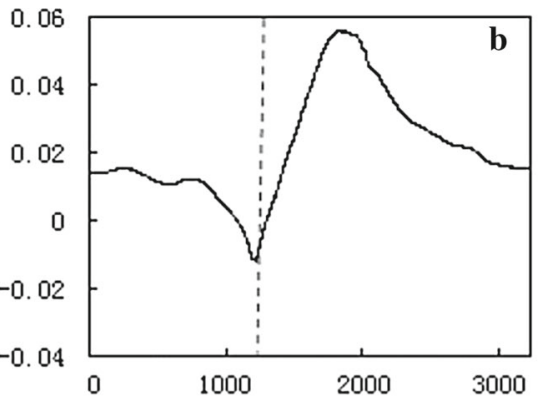

T276-5 (20100516_2010829)

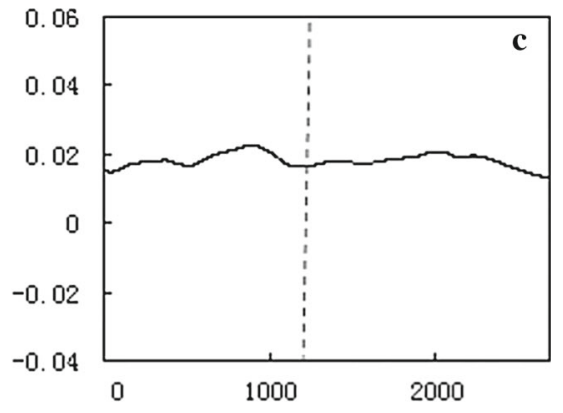

T276-6 (20100620 2010829)

Figure 12. Displacement profiles across the fault from the T276 interferograms. Locations of profiles are shown in figure 11.

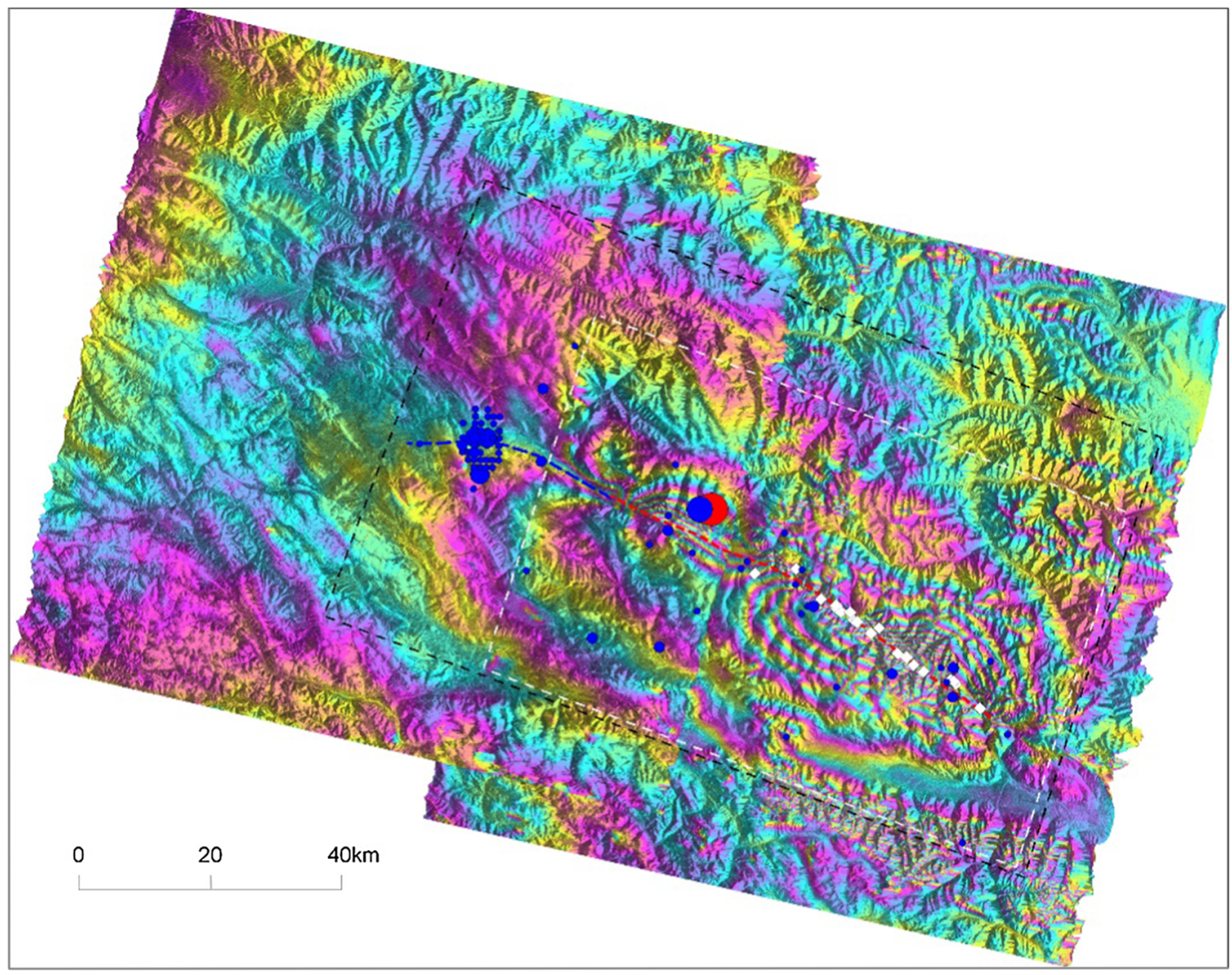

Figure 13. Mosaicked interferogram of T004-1 and T276-1. The red circle is Ms 7.1 Yushu mainshock and the blue dots are its aftershocks (Ms $\geq 3.0$, as of 23 June 2010). White diamonds denote locations of field investigations. The red dashed line is the interpreted fault trace, of $71 \mathrm{~km}$ length, from T004 alone, and the blue dashed line is that of T276, with length 32 $\mathrm{km}$. The large black dashed box shows the deformation area obtained by mosaicking T004-1 and T276-1, and the dashed white box is the deformation area given by T004 alone.

fault associated with the Yushu earthquake better.

\section{Discussion}

It is usually accepted that aftershocks occur on the same fault as the mainshock that induces the aftershocks. Sometimes, the stress released by the mainshock can initiate aftershocks on the adjacent faults (Tan et al. 2005). For the 2010 Yushu Ms 7.1 event, there are two small-scale local deformation rings $38 \mathrm{~km}$ west of the mainshock. Between these two rings, an aftershock cluster appeared with 47 events, including three main ones: Mw 5.8, $\mathrm{Mw} 5.5$ and $\mathrm{Mw}$ 5.1. We suggest that the local deformations are likely to have been generated by aftershocks. Tobita et al. (2011) considered it as a 


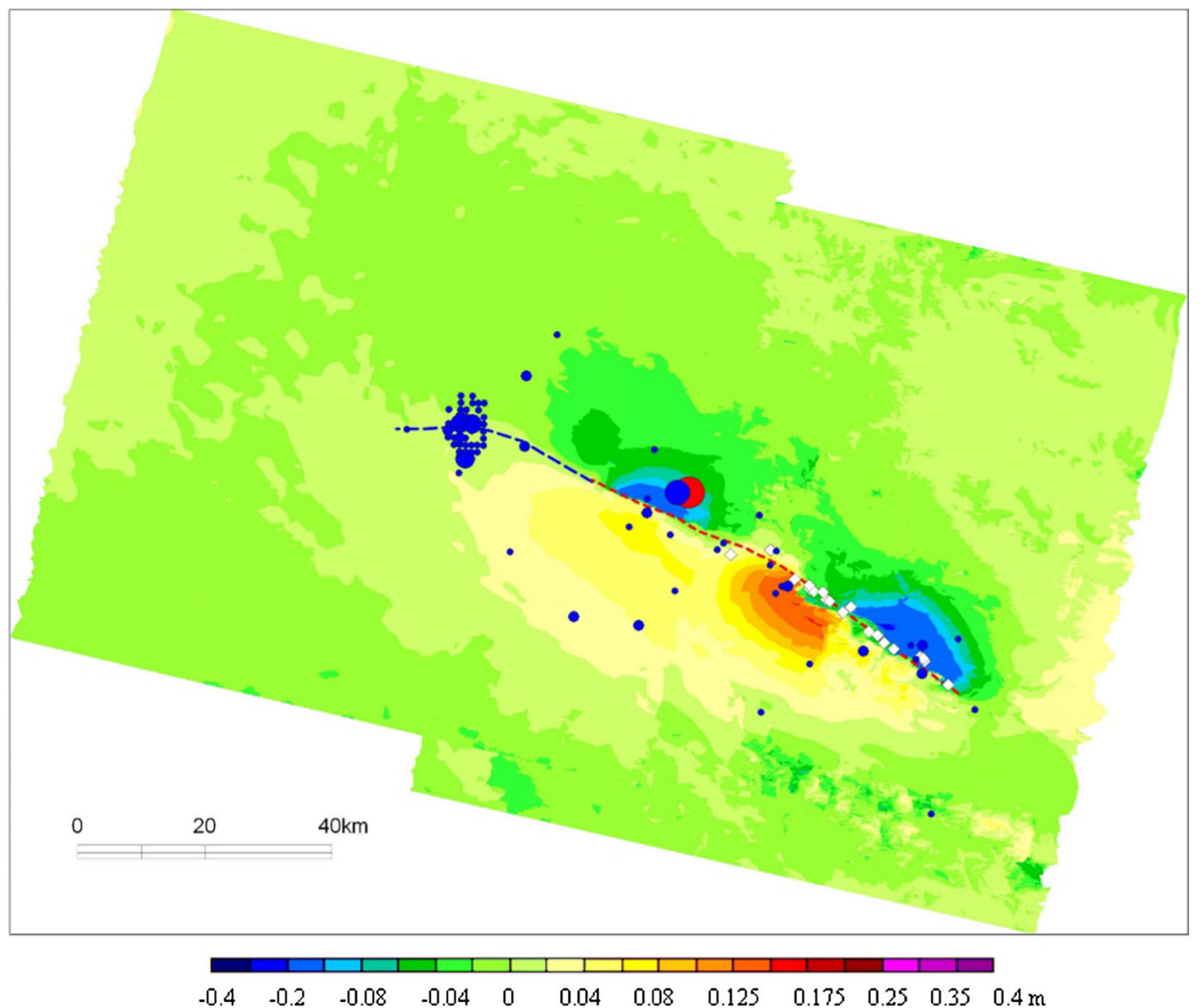

Figure 14. Unwrapped coseismic surface displacement from mosaicked T004-1 and T276-1. The red circle is Ms 7.1 Yushu mainshock and the blue dots are its aftershocks (Ms $\geq 3.0$, as of 23 June 2010). The red dashed line is the interpreted fault trace from the T004 interferogram. The black dashed line is the interpreted fault trace from the T276 interferogram.

post-seismic slip, which is spatially isolated from the coseismic deformation. In our view, the postseismic deformation in the short term, whether from post-seismic slip or post-seismic rebound, should occur within the deformation area of the mainshock, rather than outside of it. Between the two deformation rings, steep but continuous gradients are present on the displacement profiles, implying that no conspicuous surface ruptures have been produced there. On the other hand, the aftershock cluster may represent an active fault or a hidden one. Although such a fault is absent in the existing map of active faults in China, this remains a noteworthy issue.

Coseismic interferograms contain many kinds of deformation components, such as mainshock coseismic, aftershock and post-seismic displacements. Of these, the coseismic deformation generated by the mainshock is dominant in both the range and displacement amplitude. For example, in the $2010 \mathrm{Mw} 6.9$ Yushu event, the coseismic deformation across the fault covers $110 \mathrm{~km} \times$
$74 \mathrm{~km}$, with LOS displacement of $45 \mathrm{~cm}$, while that of the aftershocks is only $19.5 \mathrm{~km} \times 11 \mathrm{~km}$ with LOS displacement of less than $9 \mathrm{~cm}$. Postseismic slip is much smaller, with relative deformation between the two fault walls less than 2 $\mathrm{cm}$. The deformation of both the aftershocks and post-seismic slip appears very small with respect to the coseismic deformation by the mainshock. Despite the different time baselines of the coseismic image pairs, the resulting coseismic deformation fields derived from these interferograms are largely identical. This means that the time baselines have little effect on the overall pattern and amplitude of the coseismic deformation field. The post-seismic interferograms may reflect deformation by aftershocks or by afterslip. The former is relatively small in the spatial range, with larger displacement and distinct boundaries. The latter may appear over a larger range but with very small displacement. Both can be distinguished using InSAR data of different time intervals. 


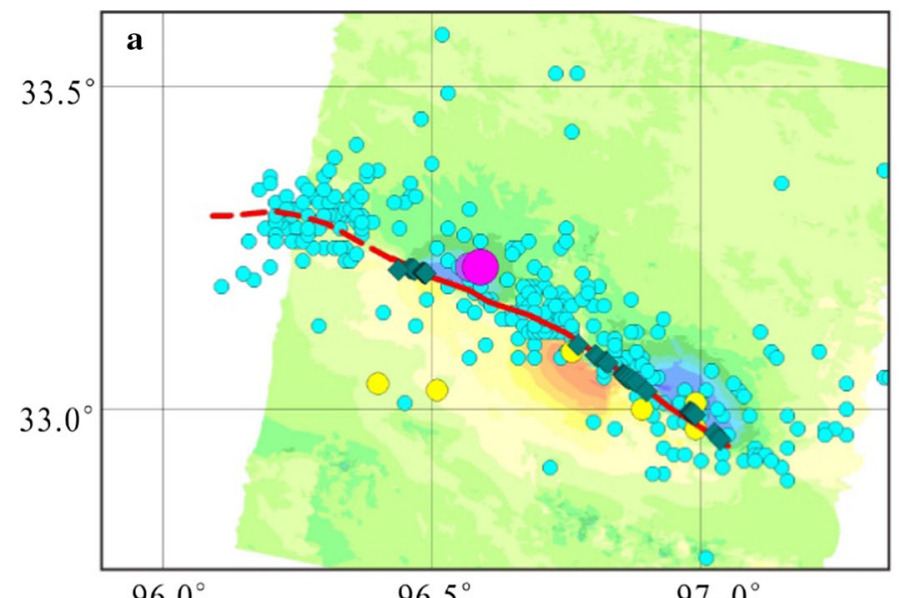

$96.0^{\circ}$

$96.5^{\circ}$

97. $0^{\circ}$

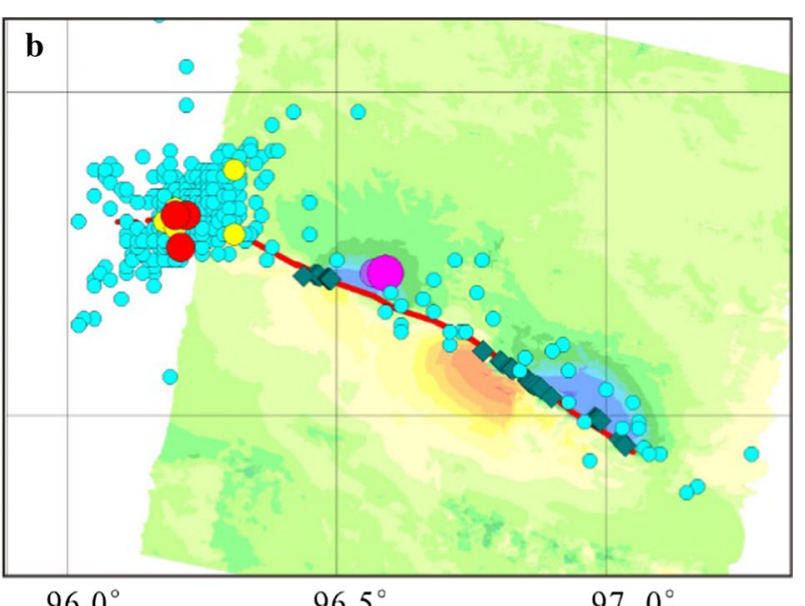

Figure 15. (a) Aftershocks distribution before 29 May 2010. Background is coseismic interferogram generated from ENVISAT/ASAR data, (b) Aftershocks distribution occurred on 29 May and later to 23 June 2010. Red line denotes surface rupture derived from previous study. Red dashed line represents surface rupture added in this study. Big pink dot shows epicentre of Yushu mainshock from USGS. Purple dots mark aftershocks with magnitude of Mw 6.0-6.9. Red dots show aftershocks with magnitude of Mw 5.0-5.9. Yellow dots are aftershocks with magnitude of Mw 4.0-4.9. Sky-blue dots represent aftershocks with magnitude smaller than Mw 4.0. Grey green diamond denotes field investigation sites.

The locally magnified coseismic interferograms (figure 5) reveal a ring-shaped local deformation area, $3 \mathrm{~km}$ southwest of Jiegu town (macroepicentre of the 2010 Yushu $\mathrm{Mw}$ 6.9), with a diameter of $12-13 \mathrm{~km}$ and displacement of approximately $8 \mathrm{~cm}$ (almost three fringes) - indicative of subsidence in the LOS direction, opposite the coseismic deformation. As there are ML 3.6 and Ms 4.8 aftershocks on its west and north margins, this inverse deformation can likely be attributed to the aftershocks. This type of post-seismic deformation is not seen on the interferograms with longer time intervals after the mainshock. One possible explanation for this is that post-seismic elastic rebound made the aftershock-induced subsidence attenuate steadily and consequently the interferograms from a later time no longer exhibit this deformation. Alternatively, this ring-shaped local deformation could be atmospheric noise rather than seismic deformation; this interpretation is more convincing.

To further investigate the relationship between displacement field in the west of Longbao lake and aftershock sequence, we give a brief analysis of aftershock sequence temporally and spatially (figure 15). The result shows that the aftershocks that occurred before 29 May 2010 have smaller magnitude (only six Ms 4.0-4.9 aftershocks and the magnitude of the other aftershocks is smaller than Ms 3.0) and evenly distributed along the NW Ganzi-Yushu fault, while the aftershocks that occurred on and after 29 May 2010 have more concentrated distribution about $35 \mathrm{~km}$ west of the epicentre of mainshock, including three moderate strong aftershocks, which are 29 May M w 5.8, 3 July Mw 5.5 and 4 July Mw 5.1 earthquakes. In this study, we use the ASAR images acquired from 16 May 2010 and 29 August 2010 to reveal the displacement field caused by these moderate strong aftershocks (figures 10a, b and 11a, b). The results show that the obvious displacement field in the west of Longbao lake is in good agreement with the aftershock sequence both spatially and temporally, so we can confirm the obvious displacement is induced by these aftershocks. It should be noticed that the distribution direction of these aftershocks have changed into NEE compared with the mainshock and previous aftershock sequences, which is also indicated by the focal mechanism solutions of three moderate strong aftershocks (table 2). We can infer that the secondary buried fault ruptured the western part to the mainshock deformation field and these aftershocks are triggered by the mainshock after 1 month. This NE strike fault may resist the rupture propagation of mainshock and change the direction of mainshock rupture zone subsequently. The result of static Coulomb stress changes in Wen et al. (2013) also indicates that the aftershocks after 29 May are mainly located in the zones of increased stress, which is an evidence to the findings in this study. We will demonstrate the detailed characteristics of this buried fault, slip distribution and the relationship to mainshock in the forthcoming paper. 
Table 2. Focal mechanism solutions for mainshock and aftershocks with magnitude more than Mw 5.0 from the Global CMT, US Geological Survey (USGS) and CENC (China Earthquake Networks Center).

\begin{tabular}{lllcccccrrrr}
\hline Model & Long. & Lat. & Depth & Mw & Strike1 & Dip1 & Rake1 & Strike2 & Dip2 & Rake2 & Note \\
\hline USGS & 96.666 & 33.224 & 17 & 6.9 & 209 & 58 & 175 & 301 & 86 & 32 & Mainshock April 14th \\
GCMT & 96.79 & 33.05 & 20 & 6.9 & 210 & 67 & 178 & 300 & 88 & 23 & \\
CENC & 96.6 & 33.2 & 14 & Ms 7.1 & 119 & 83 & -2 & 209 & 88 & -173 & 155 \\
GCMT & 96.53 & 33.18 & 17.9 & 6.1 & 296 & 65 & 2 & 205 & 89 & Aftershock April 14th \\
GCMT & 96.28 & 33.2 & 20.8 & 5.8 & 75 & 88 & 1 & 345 & 89 & 178 & Aftershock May 29th \\
GCMT & 96.28 & 33.23 & 23.9 & 5.5 & 178 & 80 & 177 & 268 & 87 & 10 & Aftershock June 3th \\
GCMT & 96.25 & 33.24 & 24.4 & 5.1 & 171 & 82 & -173 & 80 & 83 & -8 & Aftershock June 4th
\end{tabular}
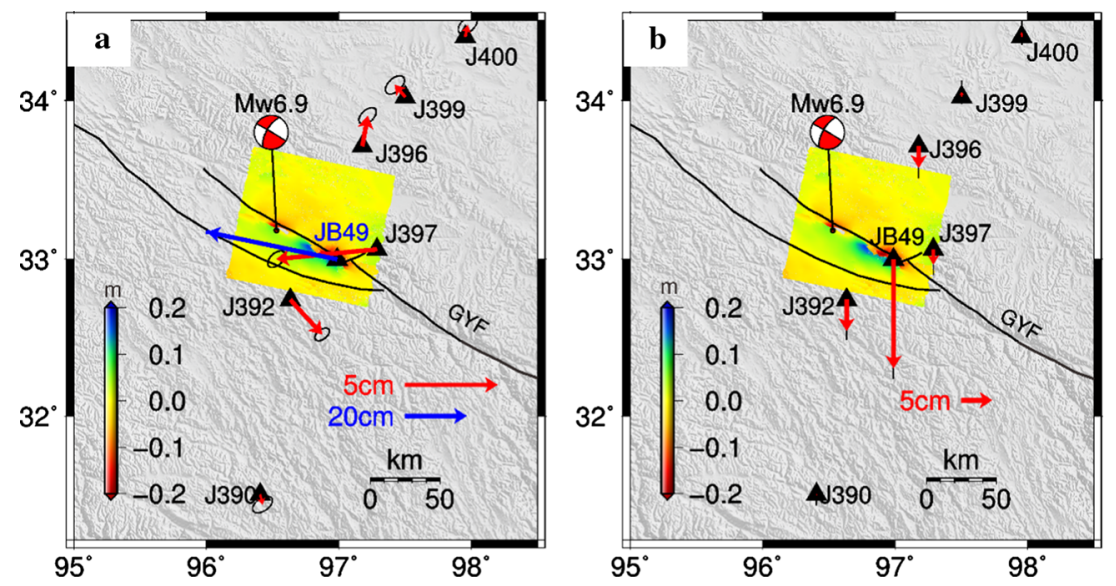

Figure 16. Comparison of GPS stations and ENVISAT/ASAR observations. The black line denotes the Ganzi-Yushu fault (GYF). The black triangles represent the GPS stations (Meng et al. 2013). The beachball is the focal mechanism solution of 14 April 2010 Mw 6.9 main shock. Ellipses are 95\% confidence interval. (a) The horizontal coseismic displacement of seven stations. (b) The vertical coseismic displacement of seven stations. Background is InSAR coseismic displacement of T004.

Global positioning system (GPS) sites were sparsely distributed in Yushu area prior to 14 April 2010 earthquake. There are a total of seven stations located approximately along the NS direction profile within $250 \mathrm{~km}$ around the epicentre. The observation and data processing of GPS datasets have already been described in detail in a previous paper (Meng et al. 2013), we just present data briefly here (figure 16). The obvious coseismic displacement can be observed in the sites JB49, J397 and J392, but only one GPS observation, JB49, is located in the deformation field acquired by InSAR and the coseismic displacement of this station is relatively reliable. Based on the three dimensional geometry of InSAR observation, we can project the three dimensional observation of GPS into the LOS component, which is about $-0.32 \mathrm{~m}$, corresponding well to the result of InSAR observations (figure 14) in this study.

Several studies (Li et al. 2011; Tobita et al. 2011; Zha et al. 2011; Qu et al. 2013) revealed the coseismic displacement field and rupture length of this event based on the InSAR analysis, and calculated the slip distribution using different fault geometries. Some differences exist, however, the coseismic rupture length of inversion results in these studies falls in the range of 70-80 km, which excludes the deformation area and rupture zone in the west of Longbao lake induced by the aftershock sequence. Indeed, a series of moderate strong aftershocks occurred after 29 May, including 29 May Mw 5.8, 3 June Mw 5.5 and 4 June Mw 5.1 earthquakes, which form the obvious deformation field on the ground (figures 10a, b and 11a, b). The previous studies only used the spatially and temporally limited InSAR data, and did not observe the overall deformation field and rupture length caused by this event as well as subsequent aftershocks. The overall estimated rupture length in the Ganzi-Yushu fault induced by the mainshock and aftershocks is $\sim 100 \mathrm{~km}$ in this study, which approximately equals the length of aftershocks distribution. The $35-\mathrm{km}$ rupture zone located in the west of Longbao lake has not been revealed by the InSAR, GPS and field investigations in the previous studies. We use the multi-tracks and multi-temporal 
InSAR data to investigate the characteristics of deformation and overall rupture length caused by the mainshock and aftershocks, as well as to study the evolution of coseismic and post-seismic deformation, which can gain the insights of activity and seismic hazard of Ganzi-Yushu fault.

\section{Conclusions}

The objective of this work is to make a comprehensive analysis of the coseismic, aftershock and post-seismic deformations associated with the 2010 Mw 6.9 Yushu earthquake. We used eight scene images from two descending tracks (T004 and T276) of ENVISAT/ASAR to generate six coseismic and six post-seismic interferograms. The results show that the deformation area derived from mosaicked (T004 and T276) interferograms is $110 \mathrm{~km} \times 74 \mathrm{~km}$, which is larger than that derived from single track (T004) data $(87 \mathrm{~km} \times 57 \mathrm{~km})$ in our previous work. The resultant fault rupture zone is $103 \mathrm{~km}$ long, which is also larger than that from the T004 data alone $(71 \mathrm{~km})$. The coseismic interferograms from images with different time intervals reveal a largely identical deformation pattern. The largest deformation appears at Jiegu town in Yushu county, southeast of the mainshock epicentre. The LOS subsidence on the north wall and LOS uplift on the south wall imply left-slip along the fault. It seems that the aftershocks and post-seismic slip did not change the pattern of coseismic deformation. On the post-seismic interferogram (T276), clear fringes reveal a local deformation area $38 \mathrm{~km}$ west of the mainshock epicentre, which is $9.5 \mathrm{~km} \times 11 \mathrm{~km}$ in size with displacement up to $9 \mathrm{~cm}$ and motion sense of left-slip too. This local deformation area consists of two patches, between which an aftershock cluster, at least 47 events (Ms $\geq 3.0$ ) in total, run through. Therefore, this local deformation is presumably caused by aftershocks. In its middle, a transition between LOS subsidence and uplift might suggest existence of a hidden active fault. Nearby the mainshock epicentre, strip-like postseismic deformation, same as the coseismic sense, but less than $2 \mathrm{~cm}$ is seen along the fault, which is likely attributed to afterslip. On the interferograms from the image pairs relatively more behind the mainshock, fringes show very small deformation, less than $1 \mathrm{~cm}$, indicating short-term post-seismic deformation primarily concentrated near the fault and attenuating rapidly over time.

\section{Acknowledgements}

The authors would like to thank the ESA (European Space Agency) for providing the ENVISAT/ ASAR data. This research was jointly supported by the National Natural Science Foundation of China (41872229) and projects of the National Key Laboratory for Earthquake Dynamics (LED2015A03) and the Basic Scientific Funding of Institute of Geology, China Earthquake Administration (IGCEA1809).

\section{References}

Chen L C, Wang H, Ran Y K, Sun X Z and Su G W 2010 The Ms 7.1 Yushu earthquake surface ruptures and historical earthquakes; Chinese Sci. Bull. 55 1200-1205.

Deng Q D 2007 Map of active tectonics in China; Seismological Press, Beijing.

Gan W J, Zhang P Z, Shen Z K, Niu Z J, Wang M, Wang Y G, Zhou D M and Cheng J 2007 Present-day crustal motion within the Tibetan Plateau; J. Geophys. Res. 112(B08416).

Guo H D, Wang X Y and Li X W 2010 Yushu earthquake synergic analysis study using multi-model SAR datasets; Chinese Sci. Bull. 55(31) 3499-3503.

Li M F, Xing C Q, Cai C X, Guo W X, Wu S X and Yuan Z Z 1995 Research on activity of YuShu fault; Seismol. Geol. 17 218-224.

Li Z H, Elliott J R, Feng W P, James A J, Barry E P and Richard J W 2011 The 2010 Mw 6.8 Yushu (Qinghai, China) earthquake: Constraints provided by InSAR and body wave seismology; J. Geophys. Res. 116(B10302).

Liu Y H, Shan X J, Qu C Y and Zhang G F 2010a Earthquake deformation field characteristics associated with the 2010 Yushu Ms 7.1 earthquake; Sci. China Ser. D: Earth Sci. 54(4) 571-580.

Liu C, Xu L S and Chen Y T 2010b Quick moment tensor solution for 14 April 2010 Yushu, Qinghai, earthquake; Acta Seismol. Sin. 32(3) 366-368 (in Chinese with English abstract).

Meng G J, Ren J W, Su X N, Yang Y L, Zhu Z, Ge L L and Li X J 2013 Coseismic deformation of the $2010 \mathrm{Mw} 6.9$ Yushu earthquake derived from GPS data; Seismol. Res. Lett. 84(1) 57-64.

Peng H, Ma X M and Bai J Q 2006 Characteristics of quaternary activities of Garze-Yushu fault zone; J. Geomech. 12 295-304.

Qu C Y, Zhang G F, Shan X J, Zhang G H, Liu Y H and Song X G 2013 Coseismic and post-seismic deformation fields of the 2010 Yushu, Qinghai Ms 7.1 earthquake and their evolution processes; Chinese J. Geophys. 56(7) 1-11 (in Chinese with English abstract).

Shen Q, Qiao X J, Wang Q, Zhang J F and Tan K 2010 Characteristic analysis of coseismic deformation of Yushu Mw 6.9 earthquake from InSAR images; J. Geod. Geodyn. 30(3) 5-9.

Sun X Z, Xu X W, Chen L C, Tan X B and Yu G H 2012 Surface rupture features of the 2010 Yushu earthquake 
and its tectonic implication; Chin. J. Geophys. 55(1) 155-170 (in Chinese with English abstract).

Tan K, Wang Q and Wang X Q 2005 Analytic models and space-time distribution of post-seismic deformation; $J$. Geod. Geodyn. 25(4) 23-26.

Tobita M, Nishimura T, Kobayashi T, Hao K T and Shindo Y 2011 Estimation of coseismic deformation and a fault model of the 2010 Yushu earthquake using PALSAR interferometry data; Earth Planet. Sci. Lett. 307 430-438.

Wen X Z, Xu X W, Zheng R Z, Xie Y and Wan C 2003 Average ship-rate and recent large earthquake ruptures along the Garze-Yushu Fault; Sci. China 33 199-208.

Wen Y M, Xu C J, Liu Y and He P 2013 Coseismic slip in the 2010 Yushu earthquake (China), constrained by wideswath and strip-map InSAR; Nat. Hazards Earth Syst. Sci. 13 35-44.

Corresponding editor: N V Chalapathi RaO
Werner C, Wegmüller U, Strozzi T and Wiesmann A 2000 Gamma SAR and interferometric processing software; In: Proceedings of the ERS-Envisat symposium 1620(1620), Gothenburg, Sweden, 16-20 October, 2000.

Zha X J, Dai Z Y, Ge L L, Zhang G, Li X J, Chen X F, Li Z H and Fu R S 2011 Fault geometry and slip distribution of the 2010 Yushu earthquakes inferred from InSAR measurement; Bull. Seismol. Soc. Am. 101(4) 19511958.

Zhang P Z, Deng Q D, Zhang G M, Ma J, Gan W J, Min W, Mao F Y and Wang Q 2003 Active tectonic blocks and strong earthquakes in the continental of China; Sci. China 33 12-20.

Zhang Y, Xu L S and Chen Y T 2010 Fast inversion of rupture process of the 14 April 2010 Yushu, Qinghai, earthquake; Earthq. Sci. 23 201-204. 